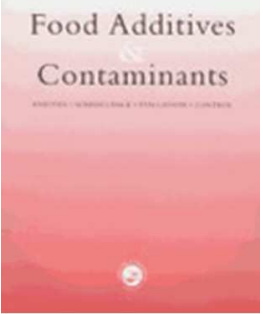

\title{
Confirmatory Method for the Determination of Streptomycin and Dihydrostreptomycin in Honey by LC-MS/MS
}

\begin{tabular}{|c|c|}
\hline Journal: & Food Additives and Contaminants \\
\hline Manuscript ID: & TFAC-2011-346.R1 \\
\hline Manuscript Type: & Original Research Paper \\
\hline Date Submitted by the Author: & $17-$ Oct-2011 \\
\hline Complete List of Authors: & $\begin{array}{l}\text { Bohm, Detlef; Federal Office of Consumer Protection and Food Safety, NRL } \\
\text { for Contaminants and Residues } \\
\text { Stachel, Carolin; Federal Office of Consumer Protection and Food Safety, } \\
\text { NRL for Contaminants and Residues } \\
\text { gowik, petra; Federal Office of Consumer Protection and Food Safety, NRL } \\
\text { for Contaminants and Residues }\end{array}$ \\
\hline Methods/Techniques: & Chromatography - LC/MS, Clean-up, Extraction, Method validation \\
\hline Additives/Contaminants: & Veterinary drug residues - antibiotics \\
\hline Food Types: & Honey \\
\hline Abstract: & $\begin{array}{l}\text { The method was specifically developed for the determination and } \\
\text { confirmation of streptomycin and dihydrostreptomycin in different types of } \\
\text { honey. The method is simple, rapid, sensitive and was validated for } \\
\text { streptomycin and dihydrostreptomycin in accordance with } \\
\text { Commission.Decision } 2002 / 657 / E C \text {. After extraction with phosphate buffer } \\
\text { and a pH change, the clean-up was performed by way of SPE with } \\
\text { polymeric phase. The LC-MS/MS analysis was carried out testing two } \\
\text { different HILIC columns for the separation of the analytes and using a } \\
\text { triple quadrupole mass spectrometer in positive ESI mode to measure the } \\
\text { transitions of the substances in MRM mode. For the quantification of both } \\
\text { substances matrix calibration curves in the linear range of } 5-80 \mu \mathrm{g} / \mathrm{kg} \\
\text { were used. The calculated validation parameters for streptomycin and } \\
\text { dihydrostreptomycin like CCa }(11.8 \text { and } 11.5 \mu \mathrm{g} / \mathrm{kg}) \text {, CC }(18.9 \text { and } 19.9 \\
\mu \mathrm{g} / \mathrm{kg} \text { ) and the recovery ( } 97 \text { and } 101 \%) \text { respectively the relative within- } \\
\text { laboratory reproducibility RSDwR }(16.4 \text { and } 20.8 \%) \text { at the recommended } \\
\text { concentration of } 40 \mu \mathrm{kg} \text { fulfil the requirements of Commission Decision } \\
2002 / 657 / E C \text {. } \\
\text { Keywords: streptomycin, dihydrostreptomycin, honey, LC-MS/MS, } \\
\text { validation, CD } 2002 / 657 / E C, C C a, C C \beta\end{array}$ \\
\hline
\end{tabular}




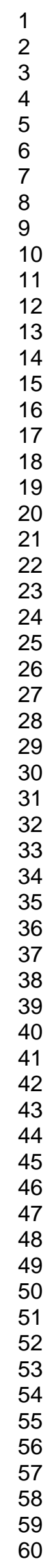

SCHOLARONE ${ }^{\text {m }}$

Manuscripts

10

11

12

14

15

16

18

19

20

21

23

24

26

27

29

30

33

34

35

36

39

40

42

43

44

45

46

47

48

50

51

52

53

54

55

57

58

59

http://mc.manuscriptcentral.com/tfac Email: fac@tandf.co.uk 


\section{Confirmatory method for the determination of streptomycin and}

\section{2 dihydrostreptomycin in honey by LC-MS/MS}

3

4 D. A. Bohm*, C. S. Stachel and P. Gowik

5

6 Federal Office of Consumer Protection and Food Safety (BVL, )

7 National Reference Laboratories for Contaminants and Residues,

$8 \quad$ Mauerstr. 39-42, 10117 Berlin, Germany 
9 Abstract

10 The method was specifically developed for the determination and confirmation of streptomcin 11 and dihydrostreptomycin in different types of honey. The method is simple, rapid, sensitive 12 and was validated for streptomycin and dihydrostreptomycin in accordance with Commission

Keywords: streptomycin, dihydrostreptomycin, honey, LC-MS/MS, validation, CD 2002/657/EC, CC $\alpha$, CC $\beta$

\section{Introduction}

Streptomycin is an aminoglycoside antibiotic that is particularly active against aerobic gram-negative bacteria. The toxicology of streptomycin is well-studied and several cases of allergic reactions have been reported. As a veterinary drug, streptomycin is authorised for use in cattle and pigs, but it is not allowed for the treatment of bees (European Commission 2010). Residues of streptomycin have to be controlled in various food products such as meat, milk, apples and honey. As a pesticide this substance can be used for the treatment of fire blight, which is amongst common diseases in apples. Streptomycin may be found in honey, 
35 because bees may transfer it from the apple tree to the beehive. However, it may also origi-

36

37

38

39

40

41

42

43

44

45

46

47

48

49

50

51

52

53

54

55

56

57 nate from an illegal treatment of the bees with this antibiotic substance. Dihydrostreptomycin is a derivative of streptomycin and was included into the method, because according to the National Residue Control Plan, both aminoglycosides have to be analysed in honey. In the last few years some methods have been published for the determination of streptomycin in food of animal origin (Berrada et al. 2010; Bogialli et al. 2005; Gallina et al. 2005; Gaudin et al. 2005; Gaugain-Juhel et al. 2009; Granja et al. 2009; Hammel et al. 2008; Lee et al. 2007; McGlinchey et al. 2008; Turnipseed et al. 2009; Van Bruijnsvoort et al. 2004; Zhu et al. 2008).

This paper describes a method with SPE clean-up step and LC-MS/MS measurement without fluoric components, which are known to possibly cause unfavourable effects such as peak suppression. In combination with the use of the HILIC column, satisfactory chromatograms are obtained.

As part of our responsibility as German National Reference Laboratory for residues of veterinary drugs, we developed a method which is suitable to confirm and quantify streptomycin and dihydrostreptomycin in honey samples. This serves to detect cases of misuse of these substances in the beehive. Therefore the method was validated in accordance with Commission Decision 2002/657/EC (European Commission 2002).

\section{Materials and Methods}

\section{Chemicals}

6 Streptomycin (STR) and dihydrostreptomycin (DSTR) were purchased from Ehrenstorfer

7 (Augsburg, Germany). LC-grade acetonitrile $(\mathrm{ACN})$ and methanol $(\mathrm{MeOH})$ were obtained 8 from LCS (Amsterdam, The Netherlands). LC-grade water was bought from Biosolve (Valkensward, The Netherlands). Hydrochloric acid $(\mathrm{HCl})$, sodium hydroxide $(\mathrm{NaOH})$, potas- 
60 sium dihydrogen phosphate $\left(\mathrm{KH}_{2} \mathrm{PO}_{4}\right)$, acetic acid, formic acid, trichloracetic acid (TCA) and

61 titriplex III (Na2EDTA x $2 \mathrm{H}_{2} \mathrm{O}$ ) were purchased form Merck (Darmstadt, Germany). Solid62 phase extraction (SPE) was performed by means of Oasis HLB cartridges (200 mg, $6 \mathrm{ml})$ 63 from Waters (Milford, MA, USA).

64

65

\section{Equipment}

66

67

A vortexer and a shaker from Heidolph (Schwabach, Germany), an analytical balance from Mettler Toledo (Greifensee, Switzerland), a high-volume centrifuge from Heraeus (Hanau, Germany), an evaporator from Zymark (Idstein, Germany), a $\mathrm{pH}$ meter from WTW (Weilheim, Germany) and a vacuum station from Supelco (Deisenhofen, Germany) were used for sample preparation and extraction.

\section{Standard solutions}

Stock solutions (S0) at concentrations of $1 \mathrm{mg} \mathrm{ml}^{-1}$ were prepared by dissolving $10 \mathrm{mg}$ of streptomycin and dihydrostreptomycin in $10 \mathrm{ml}$ of water each. To prepare the working solutions, the stock solutions were diluted with water, resulting in concentrations of $100 \mu \mathrm{g} \mathrm{ml}^{-1}$ (S1) and $1 \mu \mathrm{g} \mathrm{ml}^{-1}$ (S3). The working solution S3 was used for preparing the samples for matrix calibration as well as for the spike samples.

\section{Solutions for sample preparation and mobile phases}

For the phosphate buffer solution, $1.36 \mathrm{~g}$ of $\mathrm{KH}_{2} \mathrm{PO}_{4}$ were dissolved in approximately $950 \mathrm{ml}$ of $\mathrm{H}_{2} \mathrm{O}$. The $\mathrm{pH}$ value was adjusted to 4 with $1 \mathrm{~N} \mathrm{HCl}$ using a $\mathrm{pH}$ meter. Then $0.15 \mathrm{~g}$ of $\mathrm{Na}_{2}$ EDTA $\times 2 \mathrm{H}_{2} \mathrm{O}$ and $20 \mathrm{~g}$ of TCA were added. The solution was filled up to $1000 \mathrm{ml}$ with $\mathrm{H}_{2} \mathrm{O}$. The solutions of $3 \%$ formic acid in $\mathrm{MeOH}, 5 \mathrm{~N} \mathrm{NaOH}$ in water, $0.05 \%$ formic acid in water (mobile phase component A) and $0.05 \%$ formic acid in ACN (mobile phase component B) were prepared by mixing the equivalent volumes. The reconstitution solution was prepared by mixing the components of mobile phases $\mathrm{A}$ and $\mathrm{B}$ at a ratio of 30/70 (v/v). 
86

87

88

89

90

91

92

93

94

95

96

97

98

99

100

101

102

103

104

105

106

107

108

109

110

\section{Preparation of honey samples}

Eight different laboratory samples of nearly $500 \mathrm{~g}$ of honey each were used. This quantity was necessary to produce a sufficient number of representative samples to carry out the analyses for the eight runs of the validation study. The eight samples were different with regard to the origin and colour of the honey. Four honey samples came from forest plants (heath, forest blossom, robinia, lime) and four samples came from field plants (spring blossom, rape, buckwheat, sunflower). Four of these eight honey samples had a dark colour and four had a light colour. The samples were stored in a refrigerator at approximately $+4{ }^{\circ} \mathrm{C}$ to avoid any kind of thermal stress. The laboratory samples were divided into $1 \mathrm{~g}+/-1 \%$ test samples. The test samples were spiked with different volumes of the S3 working solution mix of streptomycin and dihydrostreptomycin $\left(1 \mu \mathrm{g} \mathrm{ml}^{-1}\right)$. Before the next step, a waiting time of $10 \mathrm{~min}$ was to be respected.

\section{Extraction and clean-up procedure}

Twenty $\mathrm{ml}$ of phosphate buffer were added to the sample of $1 \mathrm{~g}$ of honey. Then the sample was vortexed for approximately $1 \mathrm{~min}$, shaken for $10 \mathrm{~min}$ und treated in an ultrasonic bath for $5 \mathrm{~min}$. After centrifugation at $3800 \mathrm{~g}$ for $10 \mathrm{~min}$ at $5{ }^{\circ} \mathrm{C}$, the supernatant was decanted and filtered through filter paper into a $50 \mathrm{ml}$ centrifuge tube. Then the extract was adjusted with $30 \% \mathrm{NaOH}$ to $\mathrm{pH} 7.5$ and was controlled with a $\mathrm{pH}$ meter. The extract was centrifuged and decanted a second time. The SPE cartridge was conditioned with $6 \mathrm{ml}$ of methanol and $6 \mathrm{ml}$ of water. Then the entire extract solution was applied directly onto the cartridge. After the rinsing step with $3 \mathrm{ml}$ of water, the cartridge was air-dried for $10 \mathrm{~min}$. The analyte was eluted with $6 \mathrm{ml}$ of a mix solution of $3 \%$ formic acid in methanol. Then the eluate was concentrated to dryness in a TurboVap evaporator (operation mode ,sensor and time“; water bath at $50{ }^{\circ} \mathrm{C}$, nitrogen stream at 0.4 bar). The dry residue was reconstituted in $500 \mu 1$ of a mobile phase mix (component $\mathrm{A} / \mathrm{B}=30 / 70, \mathrm{v} / \mathrm{v}$ ) using a vortex mixer. The solution was transferred into vials 
111 and centrifuged for $10 \mathrm{~min}$ at $4000 \mathrm{rpm}$. The clear solution was filtered through a micro filter,

112 carefully transferred into dark glass vials with inserts and analysed by LC-MSMS.

113

\section{LC-MS/MS analysis}

The LC-MS/MS system consisted of the LC instrument 1100 from Agilent Technolo-

116 gies (Waldbronn, Germany) with a binary pump, an autosampler, a degasser, a column oven

117 and a system controller. The LC was coupled to a triple mass spectrometer QTRAP 3200

118 from AB SCIEX (Darmstadt, Germany). As analytical columns for the separation of the ana-

119 lytes, the HILIC "Atlantis" (150 mm x $2.1 \mathrm{~mm}, 3 \mu \mathrm{m}$ particle size) and the HILIC "Mono-

120 Chrom 5 MS” from Varian $(150 \times 2 \mathrm{~mm})$, each with adequate guard, were used.

121 The separation of the analytes was performed by applying a gradient of components A

122 (water with $0.05 \%$ formic acid) and B (ACN with $0.05 \%$ formic acid) at an oven tempera-

123 ture of $30{ }^{\circ} \mathrm{C}$ and a flow rate of $0.4 \mathrm{ml} \mathrm{min}^{-1}$ without splitting. The injection volume was 20

$124 \mu$. The samples were kept in the autosampler at a temperature of $10{ }^{\circ} \mathrm{C}$. The gradient started

125 with $90 \%$ of component B for 1 min and then decreased to $10 \%$ within 5 min. This composi-

126 tion was kept for $4 \mathrm{~min}$, then increased to $90 \%$ of component B within $1 \mathrm{~min}$. With the fol-

127 lowing equilibration time of $9 \mathrm{~min}$, the resulting total run time was $20 \mathrm{~min}$. The instrument

128 parameters for the mass spectrometry measurement by means of the software "Analyst", ver-

129 sion 1.5.1, were as follows: ESI+; scan type = MRM or MRM-S; dwell-time $=100$ ms or var-

130 iable; resolution $\mathrm{Q} 1$ and Q3 = unit; gas = nitrogen; gas $1=40$ psi; gas $2=50$ psi; curtain gas

$131=30 \mathrm{psi} ;$ collision gas $=$ high; ion spray voltage $=5500 \mathrm{~V}$; source temp. $=500{ }^{\circ} \mathrm{C} ; \mathrm{CXP}=4$

$132 \mathrm{~V}$.

133 The mass spectrometry parameters applied for the substances streptomycin and dihy-

134 drostreptomycin with regard to the transitions from precursor to product ions are shown in

135 Table 1.

136 


\section{$137 \quad$ Validation of the method}

138 Validation was performed in accordance with Commission Decision 2002/657/EC

139 (European Commission 2002) on the basis of an in-house validation concept. The preparation

140 of the specific study design and the calculation of the validation experiment data were carried

141 out with the help of "InterVal" (Uhlig et al. 2003).

142 For the design of the validation study, it is necessary to select relevant factors accord-

143 ing to the requirements of the samples and the laboratory to consider major changes which

144 may occur during routine analysis. In this study for STR and DSTR in honey the seven factors

145 "origin of honey", "colour of honey", "operator", "MS/MS measurement type", "LC column”,

146 "lot of cartridge" and "duration before measurement" were varied on two levels (Table 2).

147 This results in an experimental plan of 8 different factor-level-combinations or runs (Table 3).

148 Eight different types of honey were used for the 8 runs. Commission Decision 2002/657/EC

149 (European Commission 2002) requires a validation around the MRL for authorised drugs and

150 at concentrations as low as possible for Group-A-substances. For STR and DSTR in honey no

151 MRLs exist, since these antibiotics are not allowed for the treatment of bees in Europe. There

152 are no regulations for non-authorised substances in food-producing animals concerning the

153 concentration levels to be considered during validation. Therefore the validation study of the

154 method was accomplished with a view to the recommended concentration of $40 \mu \mathrm{g} \mathrm{kg}^{-1}$ for

155 streptomycin in honey (CRL Guidance Paper 2007). For each of the 8 runs the analyses were

156 performed on 6 concentration levels for STR and DSTR respectively plus an additional matrix

157 blank sample.

158 To determine the recovery, 6 samples for each run were spiked with 5, 10, 20, 40, 60

159 and $80 \mu \mathrm{l}$ of the working mix solution of $1 \mu \mathrm{g} \mathrm{ml}^{-1}$ for STR and DSTR to obtain concentration

160 levels of $5,10,20,40,60$ and $80 \mu \mathrm{g} \mathrm{kg}^{-1}$ based on $1 \mathrm{~g}$ of sample. A total number of 56 sam-

161 ples including the matrix blank samples were analysed for the validation study. 


\section{Confirmation and quantification}

164 The confirmation of the substances streptomycin and dihydrostreptomycin was per-

165 formed on the basis of the retention times and the ratio of the intensities of the two most 166 abundant product ions obtained from the precursor ion with a signal-to-noise ration of $\geq 3: 1$

167 (Table 1). The areas of the most intensive product ions of streptomycin (m/z 263.2) and dihy168 drostreptomycin (m/z 263.3) were used for the quantification. The quantitation of the spiked 169 recovery samples was carried out with the help of matrix calibration curves on 6 concentra170 tion levels. These matrix calibration samples were spiked with $0,5,10,20,40,60$ and $80 \mu 1$ 171 of the working mix solution of $1 \mu \mathrm{g} \mathrm{ml}^{-1}$. The samples of the calibration curve were prepared 172 in the same manner as the recovery samples. Due to the use of $1 \mathrm{~g}$ of matrix, sample levels of $1730,5,10,20,40,60$ and $80 \mu \mathrm{g} \mathrm{kg}^{-1}$ honey were achieved. The matrix calibration curves of the 174 quantification for streptomycin $(r=0.999)$ and dihydrostreptomycin $(r=0.999)$ were linear 175 over the concentration range from 0 to $80 \mu \mathrm{g} \mathrm{kg}^{-1}$ (Figure 1).

\section{Results and discussion}

178 The selectivity of the LC-MS/MS method was investigated by analysing blank matrix 179 samples. The extracted ion chromatograms of the blank samples (Figure 2) did not show any 180 signals for either streptomycin or dihydrostreptomycin nor any other interfering compounds 181 at the corresponding retention time. The chromatogram of a spiked sample at half the recom182 mended concentration (CRL Guidance Paper 2007), i.e. $20 \mu \mathrm{g} \mathrm{kg}^{-1}$ for streptomycin and di183 hydrostreptomycin, showed a satisfactory peak shape for both transitions (Figure 3). In Table 1844 the results of the validation parameters according to Commission Decision 2002/657/EC 185 (European Commission 2002) are reported. All method performance parameters, e.g. the de186 cision limit $\mathrm{CC} \alpha$, the detection capability $\mathrm{CC} \beta$, the repeatability $\mathrm{s}_{\mathrm{r}}$, the within-laboratory re187 producibility $S_{\mathrm{wR}}$ and the recovery were calculated and fulfil the requirements of the above188 mentioned Decision. 
189 The method has proven to be robust. The applicability and ruggedness of the method

190 were tested by examining the influence of different factors (Tables 2 and 3). At the displayed

191 single measurement curves of the 8 runs for streptomycin and dihydrostreptomycin (Figure

192 4), no outliers were identified by means of the Grubbs test for single values and for curve

193 functions. All curves lay within the prediction interval of the 8 curves. The validation study

194 was performed within 2 weeks, hence the analytical system can be considered as being stable

195 for this time period at least.

196 The method can be applied to STR and DSTR in honey (1 g sample) in a concentra-

197 tion range of 5 to $80 \mu \mathrm{g} \mathrm{kg}^{-1}$. A sequence should be limited to 24 samples and should include

198 the unknown samples, samples for quality control and samples for matrix and standard cali-

199 bration.

200 The confirmation of the substances was possible in all samples considering the ratio of

201 the two fragment ions and the retention time. The preparation of a standard calibration curve

202 is not sufficient for the quantification of both substances. Therefore the preparation of a ma-

203 trix calibration curve is necessary for quantitative purposes. The linearity was proven by ma-

204 trix calibration in a range from 5 to $80 \mu \mathrm{g} \mathrm{kg}^{-1}$. Experiments to monitor the stability of the 205 analytes in matrix and in solution are ongoing.

206

207 Conclusions

208 The use of matrix calibration curves is necessary and suitable for quantification.

209 With a small number of experiments (56 analyses), the validation study was performed in

210 accordance with the legal requirements. The calculated relevant method performance parame-

211 ters, e.g. the decision limit $\mathrm{CC} \alpha$, the detection capability $\mathrm{CC} \beta$, the repeatability, the within-

212 laboratory reproducibility and the recovery, are in the ranges required by Commission Deci-

213 sion 2002/657/EC (European Commission 2002) and the CRL Guidance Paper (2007). 
The method is applicable for the confirmation and quantification of streptomycin and di-

215 hydrostreptomycin in honey in the framework of official residue control according to Council

216 Directive 96/23/EC (European Commission 1996) and Regulation (EC) No 882 (European

217 Commission 2004).

218

219

220

221

222

223

224

225

226

227

228

229

230

231

232

233

\section{Acknowledgements}

Special thanks to Ms. S. Mönch, Ms. M. Jüsgen and Mr. A. Petruck for their assistance.

\section{References}

Berrada H, Molto JC, Manes J, Font G. 2010. Determination of aminoglycoside and macrolide antibiotics in meat by pressurized liquid extraction and LC-ESIMS. J Sep Sci. 33(4-5):522-529.

Bogialli S, Curini R, Di Corcia A, Lagana A, Mele M, Nazzari M. 2005. Simple confirmatory assay for analyzing residues of aminoglycoside antibiotics in bovine milk: hot water extraction followed by liquid chromatography-tandem mass spectrometry. J. Chromatogr. A 1067: 93

CRL Guidance Paper 2007. CRLs view on state of the art analytical methods for national residue control plans. Published on the EU-RLs web sites.

European Commission 1996: Council Directive 96/23/EC on measures to monitor certain substances and residues thereof in live animals and animal products.

Off J Eur Comm L. 125: 1 - 28

European Commission. 2002. Commission Decision 2002/657/EC implementing Council Directive 96/23/EC concerning the performance of the analytical methods and the interpret tation of the results. Off J Eur Comm L. 221:8-36

European Commission 2004: Regulation (EC) No 882/2004 of the European Parliamant and of the Council on official controls performed to ensure the verification of compliance 
240 with feed and food law,animal health and animal welfare rules.

241 Off J Eur Comm L. 165: 1 - 141

242 European Commission. 2010. Commission Regulation (EC) 37/2010 on pharmacologically

243 active substances and their classification regarding maximum residue limits in foodstuff of

244 animal origin. Off J Eur Union L. 15:1-72

245 Gallina A, Benetti C, Biancotto G, Baggio A, Manzinello C, Dainese N, Mutinelli F. 2005.

246 Antibiotics residues in honey: validation procedure. Apiacta 40: 45

247 Gaudin V, Cadieu N, Sanders P. 2005. Results of a European proficiency test for the detection

248 of streptomycin/dihydrostreptomycin, gentamicin and neomycin in milk by ELISA and

249 biosensor methods. Anal. Chim. Acta 529: 273

250 Gaugain-Juhel M, Delepine B, Gautier S, Fourmond M.P, Gaudin V, Hurtaud-Pessel D,

251 Verdon E, Sanders P. 2009. Validation of a liquid chromatography-tandem mass spectro-

252 metry screening method to monitor 58 antibiotics in milk: a qualitative approach.

253 Food Addit Contam A. 26: 1459-1471

254 Granja R, Nino A, Zucchetti R, Nino R, Patel R, Salerno A. 2009. Determination of strepto-

255 mycin residues in honey by liquid chromatography-tandem mass spectrometry.

256 Anal. Chim. Acta 637:64

257 Hammel Y.A, Mohamed R, Gremaud E, LeBreton M.H, Guy P.A. 2008. Multi-screening

258 approach to monitor and quantify 42 antibiotic residues in honey by liquid

259 chromatography-tandem mass spectrometry. J. Chromatogr. A 1177:58

260 Lee J.B, Chung H.H, Chung Y.H, Lee K.G. 2007. Development of an analytical protocol for

261 detecting antibiotic residues in various foods. Food Chem. 105 (4):1726

262 McGlinchey T.A, Rafter P.A, Regan F, McMahon G.P. 2008. A review of analytical methods

263 for the determination of aminoglycoside and macrolide residues in food matrices.

264 Anal. Chim. Acta 624:1

265 Turnipseed S.B, Clark S.B, Karbiwnyk C.M, Andersen W.C, Miller K.E, Madson M.R. 2009. 
266 Analysis of aminoglycoside residues in bovine milk by liquid chromatography electrospray

267 ion trap mass spectrometry after derivatization with phenyl isocyanate.

268 J. of Chromatogr. B, 877: 1487-1493

269 Uhlig S, Gowik P, Radeck W. 2003. Performance of a matrix-comprehensive in-house valida-

270 tion study by means of an especially designed software. Anal. Chim. Acta 483:351

271 Van Bruijnsvoort M, Ottink S.J.M, Jonker K.M, De Boer E. 2004. Determination of strepto-

272 mycin and dihydrostreptomycin in milk and honey by liquid chromatography with tandem

273 mass spectrometry. J. Chromatogr. A 1058:137

274 Zhu W, Yang J, Wei W, Liu Y, Zhang S. 2008. Results of a European proficiency test for the

275 detection of streptomycin/dihydrostreptomycin, gentamicin and neomycin in milk by.

276 ELISA and biosensor methods. J. Chromatogr. A 1207: 29 
Figure 1. Matrix calibration curve with $0-80 \mu \mathrm{g} \mathrm{kg-1}$ for streptomycin $(r=0.999)$ and dihydrostreptomycin $(r=0.999)$

\section{$254 \times 190 \mathrm{~mm}(96 \times 96 \mathrm{DPI})$}


Figure 2. Total ion and product ion chromatograms for streptomycin and dihydrostreptomycin of blank honey sample

$254 \times 190 \mathrm{~mm}(96 \times 96 \mathrm{DPI})$ 
Figure 3. Total ion and product ion chromatograms for streptomycin and dihydrostreptomycin of honey sample spiked with $20 \mu \mathrm{g} \mathrm{kg}-1$

$$
\text { 254x190mm (96 x } 96 \text { DPI) }
$$


Figure 4. Single measurement values with curves and prediction interval (fat line) of streptomycin and dihydrostreptomycin resulting from the 8 runs of the validation study

$$
\text { 254x190mm (96 x } 96 \text { DPI) }
$$


Table 1. LC-MS/MS parameter.

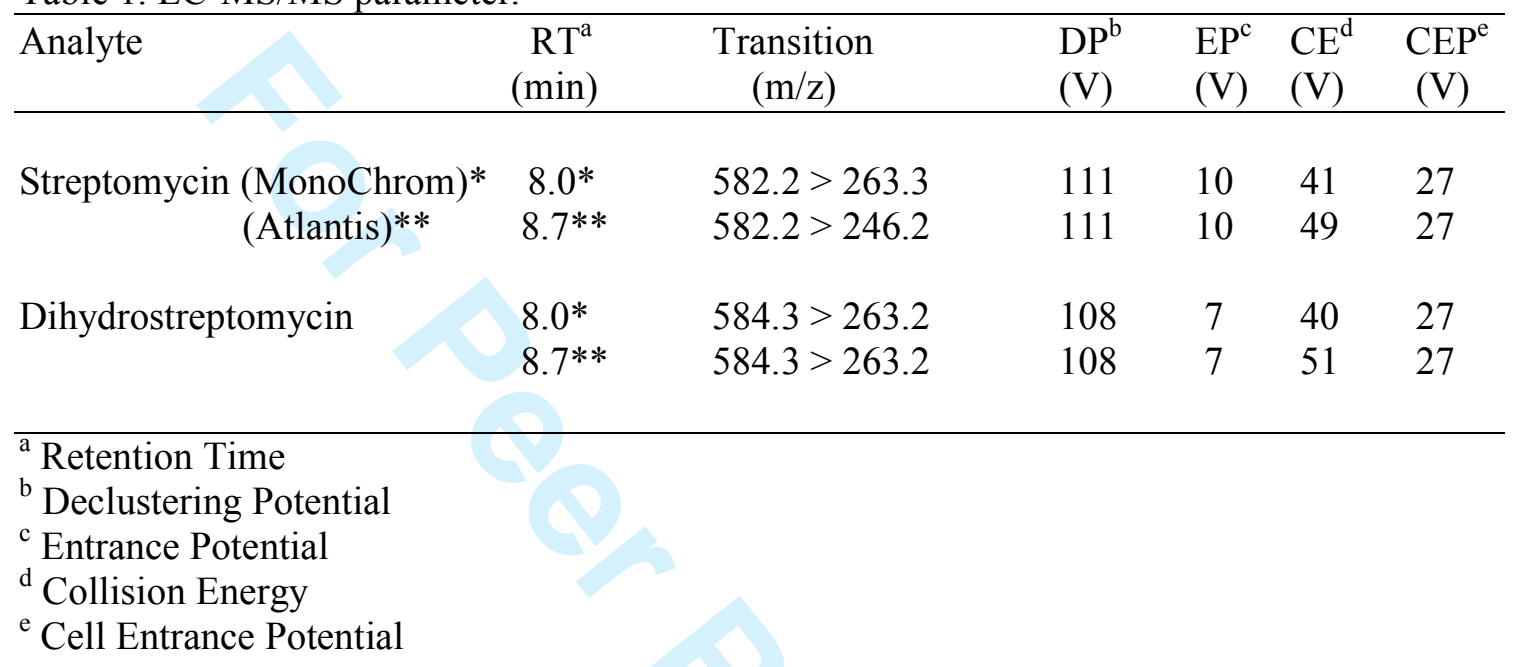


Table 2. Design of validation study: factors and levels.

\begin{tabular}{ll}
\hline Factors & Levels \\
\hline Origin of honey & field - wood \\
Colour of honey & light - dark \\
Operator & A - B \\
MS/MS measurement type & MRM - MRM-S \\
LC column & Monochrom - Atlantis \\
Lot of cartridge & Lot A - Lot B \\
Duration before measurement & directly - after $12 \mathrm{~h}$ \\
\hline
\end{tabular}


Table 3. Design of validation study: factor-level-combinations of 7 factors on 2 levels.

\begin{tabular}{|c|c|c|c|c|c|c|c|}
\hline Run & & & & Factor-lev & 1-combination & & \\
\hline No. & Origin & Colour & Operator & $\begin{array}{l}\text { MS/MS } \\
\text { type }\end{array}$ & LC column & $\begin{array}{l}\text { Lot of } \\
\text { cartridge }\end{array}$ & $\begin{array}{l}\text { Duration } \\
\text { before meas. }\end{array}$ \\
\hline 3 & field & light & B & MRM & Monochrom & Lot A & after $12 \mathrm{~h}$ \\
\hline 6 & wood & dark & A & MRM & Monochrom & Lot A & directly \\
\hline 5 & wood & dark & B & MRM & Atlantis & Lot B & after $12 \mathrm{~h}$ \\
\hline 4 & field & light & A & MRM & Atlantis & Lot B & directly \\
\hline 1 & field & dark & B & MRM-S & Monochrom & Lot B & directly \\
\hline 8 & wood & light & A & MRM-S & Monochrom & Lot B & after $12 \mathrm{~h}$ \\
\hline 7 & wood & light & B & MRM-S & Atlantis & Lot A & directly \\
\hline 2 & field & dark & A & MRM-S & Atlantis & Lot A & after $12 \mathrm{~h}$ \\
\hline
\end{tabular}


Table 4. Method performance parameters.

\begin{tabular}{llllll}
\hline Analyte & $\mathrm{CC} \alpha\left(\mu \mathrm{g} \mathrm{kg}^{-1}\right)$ & $\mathrm{CC} \beta\left(\mu \mathrm{g} \mathrm{kg}^{-1}\right)$ & $\mathrm{RSD}_{\mathrm{r}}(\%)^{\mathrm{a}}$ & $\mathrm{RSD}_{\mathrm{wR}}(\%)^{\mathrm{b}}$ & Recovery (\%) \\
\hline & & & & & \\
STR & 11.8 & 18.9 & 6.5 & 16.4 & 97 \\
DSTR & 11.5 & 19.9 & 5.2 & 20.8 & 101 \\
\hline $\mathrm{a}$ & & &
\end{tabular}

${ }^{\mathrm{a}}$ repeatability

${ }^{\mathrm{b}}$ within-laboratory reproducibility 


\section{FIGURE CAPTIONS}

Figure 1. Matrix calibration curve with $0-80 \mu \mathrm{g} \mathrm{kg}^{-1}$ for streptomycin $(\mathrm{r}=0.999)$ and dihydrostreptomycin $(\mathrm{r}=0.999)$

Figure 2. Total ion chromatogram (TIC) and product ion chromatograms for streptomycin and dihydrostreptomycin of blank honey sample

Figure 3. Total ion chromatogram (TIC) and product ion chromatograms for streptomycin and dihydrostreptomycin of honey sample spiked with $20 \mu \mathrm{g} \mathrm{kg}^{-1}$

Figure 4. Single measurement values with curves and prediction interval (fat line) of streptomycin and dihydrostreptomycin resulting from the 8 runs of the validation study 